УДК $338.1+330.5$

ББК 65.050я7

ИННОВАЦИОННАЯ ЭКОНОМИКА И ЭКОНОМИКА ИННОВАЦИЙ

\author{
С. В. КУРЕГЯН \\ kuregjian@gmail.com \\ доктор экономических наук, доцент, профессор кафедры «Экономика и право» \\ Белорусский национальный технический университет \\ г. Минск, Республика Беларусь \\ О. С. ЕЛКИНА \\ доктор экономических наук, доцент, заведующий кафедрой безопасности \\ Российская академия народного хозяйства и государственной службы \\ при Президенте Российской Федерации Северо-Западный институт управления \\ г. Санкт-Петербург, Российская Федерация \\ С. Е. ЕЛКИН \\ кандидат экономических наук, доцент, доцент кафедры безопасности \\ Российская академия народного хозяйства и государственной службы \\ при Президенте Российской Федерации Северо-Западный институт управления \\ г. Санкт-Петербург, Российская Федерация
}

Статья посвящена исследованию теоретических основ инновационной экономики и экономики инноваций. Исследовано соотношение данных понятий. Сделан вывод о том, что экономика инноваций должна ускорить создание инновационной экономики на основе проникновения инновачий во все сферы общественной жизни.

Ключевые слова: инновации, инновационная экономика, экономика инноваций, новшества, финансирование инноваций.

\title{
INNOVATIVE ECONOMY AND ECONOMY OF INNOVATIONS
}

\section{S. V. KUREGYAN}

Doctor in Economics, Associate Professor, Professor of the department "Economics and Law" Belarusian Natopnal Technical University

Minsk, Republic of Belarus

O. S. ELKINA

Doctor of Economics, Associate Professor,

Head of the department «Security»

The Russian Presidential Academy of National Economy and Public Administration

North-West Institute of Management

St. Petersburg, Russian Federation

S. E. ELKIN

$\mathrm{PhD}$ in Economics, Associate Professor,

Associate Professor of the department «Security»

The Russian Presidential Academy of National Economy and Public Administration

North-West Institute of Management

St. Petersburg, Russian Federation

The article is devoted to the study of the theoretical foundations of the innovation economy and the economy of innovation. The relation of these concepts is investigated. It is concluded that the innovation economy should accelerate the creation of an innovative economy based on the penetration of innovations into all spheres of public life. 
Keywords: innovations, innovative economics, economics of innovations, novation, innovation financing.

\section{ВВЕДЕНИЕ}

Инновационная экономика в последние годы все чаще попадает в поле зрения ученых-экономистов и становится объектом экономических исследований. Большинство авторов сходятся в том, что инновации становятся сутью современной научно-технической революции, поскольку качественные глубокие изменения в сфере науки уже недостаточны для коренных изменений в системе производительных сил общества (причем как материальных, так и духовных), для этого необходимо довести их до уровня практического применения, рынка. «Говоря о характере воздействия научно-технического прогресса на развитие белорусского социума, - справедливо подчеркивает С. Ю. Солодовников, - необходимо учитывать и обратное влияние. Переход экономики страны к информационному (постиндустриальному) технологическому этапу не может не сопровождаться становлением новой формы социальной организации общества - социально-научного сообщества. Вместе с тем, инновационная восприимчивость населения, количественное соотношение сторонников и противников новой технологической революции, соотношение людей с высшим и средним образованием, структура занятости и т. д., в свою очередь в значительной степени предопределяют возможности и темпы поступательного инновационного развития» [1, с. 444]. В связи с этим возрастает роль инноваций в современной экономике. В экономической литературе появилось много терминов, отражающих место и роль творчества в современном общественном производстве: креативная экономика, электронная экономика, новая экономика, цифровая экономика и т. п. Каждая из них имеет право на существование, но инновационная экономика среди них приобретает особое значение, ибо инновации лежат в основе всех перспективных преобразований в обществе, особенно в условиях его модернизации.

Подробный критический анализ существующих подходов и теорий инновационной экономики проведен Г. М. Бровкой [2]. Мы согласны с его оценкой, особенно используемыми им историко-политологическим и экономическим подходами, что освобождает нас от подробного рассмотрения этих вопросов. В этой статье мы акцентируем свое внимание на теоретических вопросах раскрытия сущности инновационной экономики и роли экономического анализа инновационной деятельности для ее становления.

\section{РЕЗУЛЬТАТЫ И ИХ ОБСУЖДЕНИЕ}

Инновационная экономика появляется и развивается на высоком уровне развития производительных сил общества и соответствующих им производственных отношений, основу которых составляют экономические отношения. Именно развитие последних позволяет в полной мере проявиться инновационной экономике. Поэтому инновационная экономика - это, прежде всего, инновационный потенциал общества, используемый непосредственно в процессе производства инновационных продуктов и других результатов общественного производства. Инновации служат одновременно как развитию науки, так и развитию общественного производства и тем самым выступают связующим звеном между наукой и общественным производством.

Инновационная экономика - это практическое использование результатов экономики инноваций. Экономика инновационного процесса - это использование материальных и интеллектуальных ресурсов с целью создания новых инноваций, во многом определяющих инновационный уровень общественного производства. Одной из важнейших 
характеристик инновационной экономики является высокий уровень производительности труда: «реализация модели устойчивого инновационного социально-экономического развития Республики Беларусь во многом зависит от теоретического и практического решения проблемы труда. Труд рассматривается как основа жизнедеятельности человека, как фактор производства, как источник прибыли, как источник удовлетворения общественных и личных потребностей, как условие человеческой жизни, как источник повышения эффективности и конкурентоспособности экономики» [3, с. 278]. Инновационная экономика отличается от традиционной экономики более высоким уровнем эффективности производства и большим удельным весом высокотехнологичной продукции.

Воздействие инноваций на экономику, а значит и уровень развития инновационной экономики, во многом зависит от новизны и оригинальности самих инноваций. Они могут вносить как коренные изменения в экономику, касающиеся всех отраслей производства, создавая новую технику и технологии, так и прогрессивные изменения (улучшение, усовершенствование), которые не приводят к скачкообразному развитию экономики. В первом случае это приводит к получению сверх прибылей, во втором случае увеличению прибыли в рамках данного бизнеса, но во всех случаях являются реализацией конкурентных преимуществ. Поэтому очень важно, чтобы мероприятия в области маркетинга по масштабу и глубине воздействия на рынок были адекватными возможностям, которые открывают инновации. Особенно ценны в бизнесе инновации, снижающие издержки производства, последние при всех прочих равных условиях (скажем, при тех же ценах) позволяют увеличить предложение на рынке и объем прибыли за счет роста продаж. Этим же определяется необходимость повышения квалификации работников, связанных с нововведениями, особенно долгосрочного характера. В литературе обращается внимание на проблему «повышения адаптивности развития человеческого потенциала к потребностям инновационного развития» [4, с. 12], что обусловливает необходимость поиска инструментов и методов преодоления инертности трудовых ресурсов и экономического стимулирования их инновационной активности, функцией которого на предприятии является «производство желаемого поведения работника (в данном случае - инновационного - примечание $C$. K.) с использованием определенных технологий» [5, c. 54]. При этом следует добиваться, чтобы повышение их оплаты не приводило к существенному увеличению совокупных затрат бизнеса.

Г. М. Бровка справедливо считает, что «инновационная экономика предполагает избыточное количество своей продукции: избыток знаний, идей, разработок, патентов, высоких технологий, компаний, предпринимателей, ученых, инфраструктур и т. д.» [2, c. 63]. Действительно, инновационная экономика отличается тем, что предложение инновационных продуктов и других результатов инновационной деятельности опережают спрос на них. Это, с одной стороны, расширяет возможности выбора у потребителей, а с другой - усиливает конкуренцию между производителями инновационных товаров за того же потребителя. «Для пострыночной экономики, - по справедливому замечанию С. Ю. Солодовникова, - характерно наличие высокоэффективного промышленного производства, значительное увеличение доли сектора услуг в ВВП, дальнейшее увеличение значения знаний для развития экономики, развитие интернет-технологий и новые (пострыночные) формы конкурентной борьбы» [6, с. 23]. Это касается не только инновационных, но и обычных продуктов, созданных в условиях инновационной экономики, поскольку в развитых экономиках одной из закономерностей является опережающее предложение по отношению к спросу.

Инновационные результаты удовлетворяют как личные, так и производственные потребности. Удовлетворение личных и производственных потребностей, в конечном 
итоге, получает выражение в воспроизводстве рабочей силы и творческих сил работников, либо в производительном использовании в процессе общественного производства. Ю. В. Мелешко подчеркивает: «Развитие наукоемких отраслей промышленности не может осуществлять без соответствующего развития научно-технического потенциала, основывающегося на тесной интеграции фундаментальной, прикладной и вузовской науки в промышленное производство. Использование инноваций на постоянной основе является необходимым условием успешного развития высокотехнологичных отраслей промышленности, при этом речь идет не только о технологических инновациях, но и об организационных и маркетинговых инновациях, используемых сегодня практически в любой отрасли промышленности» [7, с. 26]. Инновации, способствуя увеличению прибыли, по сути, увеличивают собственные источники финансирования бизнеса и поступления в бюджет страны для решения социальных задач и развития национальной экономики.

Инновации должны касаться, прежде всего, сферы образования. Именно здесь формируется новое экономическое мышление, понимание роли частного бизнеса в прогрессе экономики, но для этого важно, чтобы сами преподаватели обладали этим мышлением.

Большим инновационным потенциалом развития обладает и здравоохранение. Последнее невозможно без новых способов лечения, новых медицинских инструментов и препаратов. Для проведения современного лечения необходимы компьютерные системы и высокие технологии.

Инновации в другой сфере нематериального производства - в искусстве должны способствовать усилению воздействия на зрителя (потребителя) с целью обогащения его духовного мира. Но никакие технические средства не способны заменить высокохудожественный уровень произведений искусства.

Инновационная экономика отличается более высоким уровнем неопределенности, чем экономика, не достигшая этого уровня, поскольку использует в больших масштабах инновации в различных областях экономики и жизнедеятельности человека. В инновационной экономике не наблюдается разрыва между инновациями и отраслями общественного производства. Происходит взаимное проникновение техники и технологии, созданных в самом общественном производстве в сферу инноваций, а инноваций в сферу общественного производства. Инновационная экономика - это конкурентная экономика, поскольку инновации приводят к снижению издержек производства и соответственно цены на продукт, а ценовая конкуренция, как известно, является основным видом конкуренции.

На наш взгляд, прав И. Я. Левяш в том, что «становление инновационной экономики следует отнести к более высокому типу общества» [8, с. 61]. Модернизация как непрерывное изменение, улучшение и совершенствование остается необходимым условием и фактором развития инновационной экономики. «В Республике Беларусь успешность модернизации экономики, прежде всего, зависит от того, удастся ли создать в стране современный индустриальный сектор, т. е. перейти от массового производства до гибкого специализированного в ответ на технологические инновации» $[9$, с. 4]. Инновационная экономика, как ни одна экономика требует своей модернизации, поскольку с одной стороны непрерывно совершенствуется и обновляется, а с другой - неизбежно быстро устаревает, требуя модернизации производительных сил, общественных отношений и самого человека. Другими словами, модернизация нуждается в инновациях, а инновации - в модернизации. Для инновационной экономики важны не точечные интеллектуальные результаты, не отдельные прорывы в области теории и практики, а равномерное, поступательное, всеобъемлющее инновационное развитие, основанное на креативном бизнесе [10]. 
Таким образом, инновационная экономика способна сама генерировать и использовать инновационные идеи и продукты, ускоренно доводить фундаментальные и прикладные результаты до практического применения. Но для этого необходимы различные способы движения инновационных продуктов, как рыночные, так и нерыночные (администрирование), которые особенно важны в трансформационный период. Дело в том, что в старой экономической системе всегда стояла проблема внедрения новшеств в общественное производство, в результате чего они морально устаревали до внедрения в производство. Поэтому необходим отлаженный экономический механизм управления этим процессом.

В инновационной экономике важную роль должен играть частный бизнес. Частный бизнес отличается гибкостью, динамичностью и возможностью развиваться самостоятельно. Вместе с тем, развитие частного бизнеса сопряжено с большими рисками и неустойчивостью. Что касается государственного бизнеса, то он отличается большим капиталом, меньшими рисками и малой неопределенностью, носит более устойчивый характер. Государственный бизнес в целом менее предприимчив, чем частный. При этом следует учитывать, что частный бизнес не готов к широкому использованию инноваций, не располагает большим капиталом для этих целей, а государственный бизнес в свою очередь слишком бюрократизирован. Причем, и тот, и другой не всегда способствуют инновационному развитию. Развитие капиталистических отношений, решение задач первоначального накопления капитала, укрепление частного бизнеса и развитие рыночных отношений позволят постепенно преодолевать эту инертность. Особенно это касается решения крупных национальных инновационных проектов, в которых занят и государственный и частный бизнес. Поэтому государственный и частный бизнес должны дополнять друг друга. Объединение их усилий может способствовать решению инновационных задач, в частности, Ю. В. Мелешко указывает, что «с применением ГЧП решаются задачи перехода экономики на инновационный путь развития, в частности путем создания венчурных фондов, инновационных кластеров, в рамках которых обеспечивается эффективный механизм доведения научных знаний до инноваций, трансферт технологий, в том числе, между отраслей» [11, с. 40].

Следует согласиться с И. Б. Михеевой в том, что «государственно-частное партнерство в инновационной сфере можно определить как институциональный и контрактный организационный формат взаимодействия государства и бизнеса для реализации общественно значимых проектов» [8, с. 161]. Последнее особенно важно с точки зрения повышения эффективности инноваций и развития экономики инноваций в целом. Экономика инноваций - это процесс производства, распределения, обмена и потребления инновационных продуктов в виде изобретений, полезных моделей, промышленных образцов, опытных образцов и т. д., которые представляют собой объекты интеллектуальной собственности. Экономика инноваций охватывает также новшества, созданные как для собственного применения, так и реализации с целью получения определенного дохода. Экономика инноваций - это также инновационная деятельность, организация и управление инновационными процессами.

Экономика инноваций, очевидно, не может обойти и вопросы финансирования инноваций. Финансирование должно быть обоснованным и сбалансированным как по источникам, так и по объектам. Обоснованность и сбалансированность не означает, что источники или объемы финансирования не могут быть пересмотрены в зависимости от организационной, экономической ситуаций, от сложившейся рыночной конъюнктуры. Причем, особое значение приобретает проектное финансирование, которое наряду с отраслевым и региональным финансированием обеспечивает развитие инновационного процесса. При этом должны учитываться особенности инновационных проектов, их 
большая зависимость от инвестиционных возможностей, их неопределенный и вероятностный характер, особенно на стадии фундаментальных и прикладных исследований.

Использование проектного подхода не должно заменять отраслевого и регионального подхода. Его необходимо рассматривать как дополнение к ним, поэтому они должны быть взаимоувязаны. Реализация инновационных проектов во многом зависит от инвестиций. Субъектами инвестиций могут быть как государство в лице соответствующих органов, так и бизнес.

Таким образом, экономика инноваций - это также разработка, осуществление и использование инновационных проектов. Любые инновационные проекты имеют цели, этапы, стадии и результаты. Многие инновационные проекты преследуют конкретные цели, для достижения которых разрабатывается целая система мероприятий, каждое из них направлено на решение определенных социально-экономических, научно-технических и технологических задач, позволяющих в совокупности решить главную задачу реализацию замысла проекта. Для этого должно быть разработано дерево целей, где достижение низших целей дает ключ к решению более высоких и сложных задач. Все этапы и стадии, как впрочем, и весь проект, должны быть обеспечены финансовыми ресурсами. Понятно, что любой инвестор, вкладывая средства в тот или иной проект, прежде всего, думает об их окупаемости, экономической выгоде, которую сулит успешная реализация проекта. Поэтому важно, чтобы инвестор не был отстранен от этих процессов и не только для осуществления надзора, но и для повышения эффективности предпринимаемых экономических шагов.

Говоря об экономических проблемах инноваций, мы должны коснуться не только проблем финансирования, но и кадрового обеспечения инновационных процессов, в основе которых лежит инновационная деятельность. Т. В. Сергиевич обосновывает необходимость проведения организационно-управленческой модернизации, направленной на совершенствование кадрового обеспечения инновационных процессов: «финансовая поддержка и технико-технологические инновации сами по себе не могут обеспечить расширенное воспроизводство капитала предприятия. Наличие организационно-управленческих инноваций, направленных на обеспечение расширенного воспроизводства человеческого капитала, - есть предпосылка перехода к интенсивному пути развития предприятий» [12, с. 92]. Инновационное развитие невозможно также без обновления самих экономических отношений, господствующих в обществе, коренных перемен в системе материальных и духовных производительных сил общества, особенно человека - главной производительной силы общества. От его умений, навыков и духовного потенциала во многом зависит результат.

Поэтому неслучайно, что М. В. Мясникович среди базовых элементов инновационной системы выделяет систему подготовки и переподготовки кадров для инновационной деятельности [13, с. 94]. Без этого любым творческим начинаниям будут препятствовать отсталые общественные отношения, последние в свою очередь - тормозить развитие инноваций. Поэтому в одной из своих научных работ мы, с одной стороны, рассматриваем инновации как основной путь модернизации экономики, а с другой, модернизацию в качестве основы развития общественных отношений, как необходимого условия невозврата к прежним общественным отношениям [14].

\section{ВЫВОДЫ}

Экономика инноваций должна ускорить создание инновационной экономики на основе проникновения инноваций во все сферы общественной жизни - экономику, быт, 
досуг и т. д. Поэтому по мере создания социально-экономических предпосылок, инновации должны стать не только элементом, отраслью или сектором экономики, но и сутью экономической ткани общества. Последнее в свою очередь потребует постепенного расширения инновационного уклада до таких масштабов, которые позволят охватить всю экономическую систему общества в целом. Лишь только в этом случае можно будет утверждать, что инновационная экономика достигла своей зрелости.

\section{СПИСОК ИСПОЛЬЗОВАННЫХ ИСТОЧНИКОВ}

1. Солодовников, С. Ю. Социально-экономические условия перехода Республики Беларусь к постиндустриальному обществу / С. Ю. Солодовников // Известия Самарского научного центра Российской академии наук. - 2007. - Т. 9. - № 2. - С. 443-448.

2. Бровка, Г. М. Инновационная экономика и национальная безопасность: анализ формулировок и теоретическое обеспечение / Г. М. Бровка. - Кишинев. - 2016. - С. 9-33.

3. Сергиевич, Т. В. Некоторые политико-экономические аспекты исследования трудовых отношений в Республике Беларусь на современном этапе / Т. В. Сергиевич // Экономическая наука сегодня : сб. науч. ст. / БНТУ. - Минск, 2016.- № 4. - С. 278-286.

4. Солодовников, С. Ю. Теоретико-методологические основы исследования взаимосвязи теории трудовой мотивации и динамики трудовых отношений / С. Ю. Солодовников, Т. В. Сергиевич // Вестн. Полоц. гос. ун-та. Сер. D. Экон. и юрид. науки. - 2016. № 5. - С. 12-16.

5. Сергиевич, Т. В. Экономическое стимулирование производства товаров интенсивного обновления: теоретико-методологические основы / Т. В. Сергиевич // Право. Экономика. Психология. - 2017. - № 3 (8). - С. 49-55.

6. Солодовников, С. Ю. Феноменологическая природа взаимообусловленности экономической конкурентоспособности и социального капитала Беларуси и Украины / С. Ю. Солодовников // Экономическая наука сегодня : сб. науч. ст. / БНТУ. - Минск, 2015. - Вып. 3. - С. 23-34.

7. Мелешко, Ю. В. Сценарии дальнейшего развития услуг промышленного характера в Республике Беларусь / Ю. В. Мелешко // Вестн. Полоц. гос. ун-та. Сер. D. Экон. и юрид. науки. - 2016. - № 13. - С. 62-68.

8. Интеллектуальный капитал и потенциал Республики Беларусь / Е. М. Бобосов [и др.]; научн. ред. И. Я. Левяш, - Минск. Изд-во Беларуская навука. -387 с.

9. Солодовников, С. Ю. Тенденции и перспективы развития занятости и создания социально-научного сообщества в условиях модернизации транзитивной экономики: на примере Республики Беларусь / С. Ю. Солодовников // Вестн. Полоц. гос. ун-та. Сер. D. Экон. и юрид. науки. - 2015. - № 6. - С. 2-9.

10. Курегян, С. В. Креативный бизнес / С. В. Курегян. - Минск :Изд-во Право и экономика, 2016. - $156 \mathrm{c}$.

11. Мелешко, Ю. В. Основные формы сотрудничества предприятий реального сектора экономики Республики Беларусь и Российской Федерации в сфере производства космической техники / Ю. В. Мелешко // Право. Экономика. Психология. - 2018. № 1 (9). - С. 37-42.

12. Сергиевич, Т. В. Методическое обеспечение повышения экономической эффективности воспроизводственного цикла предприятия по производству товаров интенсивного обновления / Т. В. Сергиевич // Экономическая наука сегодня : сб. науч. ст. / БНТУ. - Минск, 2017. - № 6. - С. 91-107.

13. Мясникович, М. В. Республика Беларусь на пути к новой экономике / М. В. Мясникович. - Минск. Изд-во Беларуская навука. 2009. - 292 с. 
14.Курегян, С. В. Власть и экономика / С. В. Курегян. - Минск : Право и экономика, 2017. - 188 c.

\section{REFERENCES}

1.Solodovnikov, S. Ju. Social'no-jekonomicheskie uslovija perehoda Respubliki Belarus' k postindustrial'nomu obshhestvu / S. Ju. Solodovnikov // Izvestija Samarskogo nauchnogo centra Rossijskoj akademii nauk. - 2007. - T. 9. - № 2. - S. 443-448.

2.Brovka, G. M. Innovacionnaja jekonomika i nacional'naja bezopasnost': analiz formulirovok i teoreticheskoe obespechenie / G. M. Brovka. - Kishinev. - 2016. - S. 9-33.

3.Sergievich, T. V. Nekotorye politiko-jekonomicheskie aspekty issledovanija trudovyh otnoshenij v Respublike Belarus' na sovremennom jetape / T. V. Sergievich // Jekonomicheskaja nauka segodnja : sb. nauch. st. / BNTU. - Minsk, 2016.- № 4. - S. 278-286.

4.Solodovnikov, S. Ju. Teoretiko-metodologicheskie osnovy issledovanija vzaimosvjazi teorii trudovoj motivacii i dinamiki trudovyh otnoshenij / S. Ju. Solodovnikov, T. V. Sergievich // Vestn. Poloc. gos. un-ta. Ser. D. Jekon. i jurid. nauki. - 2016.-№ 5. - S.12-16.

5.Sergievich, T. V. Jekonomicheskoe stimulirovanie proizvodstva tovarov intensivnogo obnovlenija: teoretiko-metodologicheskie osnovy / T. V. Sergievich // Pravo. Jekonomika. Psihologija. - 2017. - № 3(8). - S. 49-55.

6.Solodovnikov, S. Ju. Fenomenologicheskaja priroda vzaimoobuslovlennosti jekonomicheskoj konkurentosposobnosti i social'nogo kapitala Belarusi i Ukrainy / S. Ju. Solodovnikov, // Jekonomicheskaja nauka segodnja. / BNTU. - Minsk, 2015. - Vyp. 3. - S. 23-34.

7.Meleshko, Ju. V. Scenarii dal'nejshego razvitija uslug promyshlennogo haraktera v Respublike Belarus' / Ju. V. Meleshko // Vestn. Poloc. gos. un-ta. Ser. D. Jekon. i jurid. nauki. - 2016. - № 13. - S. 62-68.

8.Intellektual'nyj kapital i potencial Respubliki Belarus' / E. M. Bobosov [i dr.]; nauchn. red. I. Ja. Levjash, - Minsk. Izd-vo Belaruskaja navuka. 387 - S. 61.

9.Solodovnikov, S. Ju. Tendencii i perspektivy razvitija zanjatosti i sozdanija social'nonauchnogo soobshhestva v uslovijah modernizacii tranzitivnoj jekonomiki: na primere Respubliki Belarus' / S. Ju. Solodovnikov // Vestn. Poloc. gos. un-ta. Ser. D. Jekon. i jurid. nauki. 2015. - № 6. - S. 2-9.

10.Kuregjan, S. V. Kreativnyj biznes. Minsk. Izd-vo Pravo i jekonomika 2016, $156 \mathrm{s.}$

11.Meleshko, Ju. V. Osnovnye formy sotrudnichestva predprijatij real'nogo sektora jekonomiki Respubliki Belarus' i Rossijskoj Federacii v sfere proizvodstva kosmicheskoj tehniki / Ju. V. Meleshko // Pravo. Jekonomika. Psihologija. - 2018. - № 1 (9). - S. 37-42.

12.Sergievich, T. V. Metodicheskoe obespechenie povyshenija jekonomicheskoj jeffektivnosti vosproizvodstvennogo cikla predprijatija po proizvodstvu tovarov intensivnogo obnovlenija // Jekonomicheskaja nauka segodnja / BNTU. - Minsk, 2017. - № 6. - S. 91-107.

13.Mjasnikovich M,V. Respublika Belarus' na puti k novoj jekonomike / M. V. Mjasnikovich. - Minsk. Izd-vo Belaruskaja navuka. 2009, 292 - s. 94.

14.Kuregjan, S. V. Vlast' i jekonomika / S. V. Kuregjan. - Minsk : Pravo i jekonomika, 2017. - $188 \mathrm{~s}$.

Статья поступила в редакцию 14 сентября 2018 года. 